\title{
DEPÓSITOS E FEIÇÕES GLACÍGENAS DO GRUPO ITARARÉ NO RIO GRANDE DO SUL, BRASIL
}

\author{
L.J. Tomazelli (IG/UFRGS-CIGO) \\ E. Soliani Jr. (IG/UFRGS-CIGO)
}

A descoberta de novas áreas de ocorrencia, no Éstado do Rio Grande do Sul, de rochas sedimentares pertencentes ao Grupo Itararé tem fornecido importantes informaços no sentido de melhorar a compreensa das caracteristicas estratigraficas desta unidade, bei como da natureza da glaciaç̆o gondwanica ocorrida na porç㐅̆o meridional da Bacia do Paraná.

Uma origem glacial para parte da sequencia sedimentar do Grupo Itararé, no Rio Grande do Sul, ja proposta por estudiosos há muitos anos (e.g. Leinz, 1937) e, igualmente, contestada par outros (e.g. Correa da Silva, 1978), foi consistentemente documentada por Tomazelli \& Soliani Jr. (1982) quando estes autores apresentaram un conjunto de evidencias que apontas para esta interpretaço. Tais evidencias, somadas a outras recentemente descobertas en novas areas, incluem extensos pavimentos estriados associados, espacialmente, a feictes e litologias tipicas de sistemas glaciais, cono: ocorrencia de diamictitos, blocos e atacós erraticos, clastos facetados e estriados, ritmitos com clastos pingados e exuberantes estruturas deformativas intraformacionais (dobras, falhas e estruturas de colapso). En sintese, quase todas as facies sedimentares e feiços normalmente encontráveis en uma area que esteve dimretanente sob a aço de geleiras foran registradas nos dilimos anos, de tal forma que a natureza glacial de parte das sequiencias do Grupo Itararé, tamben no Rio Grande do Sul, pode ser aceita com segurança.

Como se verifica em várias outras regiós, a controvérsia sobre a origem glacial ou na de determinado pacote sedimentar ten, na maioria dos casos, concentrado a atenço dos estudiosos na busca de evidencias favoráveis ou contrárias a tal genese. Com isto, a interpretaça ambiental das fácies sedimentares, sob o ponto de vista dos processos geneticos especificos atuantes dentro do sistema, bew como o estabelecimento de modelos deposicionais, tein sido temas quase ño explorados.

Neste trabalho, os autores procuran, de modo ainda preliminar, interpretar a günese de un conjunto de fácies sedimentares da unidade litoestratigráfica Itararé aflorante na regiäo de Suspiro e Batovi, sul do Municipio de săo Gabriel, procurando associatlas a processos comuns ao contexto do sistema deposicional glacial. Os afloramentos selecionados para os estudos encontram-se ao longo de uma faixa topograficamente baixa, tectonicamente controlada por estruturas com orientaço MH-SE ("Lineamento de Ibare"). As exposicbes, em geral, săo reduzidas, 1 imitadas aos fundos de vales, sendo que as melhores e 
mais continuas ocorrencias surgen nos cortes ao longo da RFFSA, entre as estacoes de Coronel Linhares e Suspiro. Messes locais, os sedimentos glacigenos, de espessuras variáreis de alguns metros a dezenas de netros, repousan discordantenente sobre rochas metanoricas do embasamento (xistos, filitos e marmores) ou sobre sedientitos mais antigos conglomerados da Formaço Harica).

A andise faciologica dos afloramentos permitiu o reconheciento de depósitos e feicoles associadas aos seguintes processos e ambientes, dentro do sistema deposicional glacial: 1. ambiente sub-glacial, representado por fácies dianictiticas (tilitos) portadoras de blocos e matacos erraticos, clastos facetados e estriados, e que se associan a pavinentos com estrias e sulcos. Tais fácies e feicbes indicai una gênese junto a regiăo basal de una geleira que se deslocava no sentido sul-norte;

2. abbiente pro-glacial de contato direto con o gelo, reconhecido por duas associasoles faciologicas relacionadas a dois diferentes sub-ambientes de contato com o gelo: (a) "outwash" subaquoso - diamictitos, conglowerados, arenitos gradacionais e lanitos depositados por fluxos gravitacionais subaquosos (fluxos de detritos e correntes de turbidez), alternados com periodos de quiescência, responsáveis pela acunulaçăo de "drapes" de laima e (b) "outwash" subaéreo - associaço de conglowerados e arenitos bew estratificados, en corpos lenticulares limitados por superficies erosivas, gerados por fluxos aquosos trativos, de alta energia. E significativa a presença nesses afloramentos, de estruturas de colapso (falhas) e outras feicoses resultantes da fusăo gradual de blocos estagnados de gelo;

3. abbiente pro-glacial lacustrino, representado por arenitos finos e siltitos con laninaço ondulada cavalgante ("climbing ripples") resultantes de correntes trativas de fundo associadas a frentes deliaicas. Kitmitos siltico-argilosos, finamente laminados, com clastos pingados, depositados por suspensăo nas partes mais centrais dos lagos (varvilos). São marcantes as estruturas deformativas de grande porte (dobras e falhas) afetando deterinados intervalos das sequencias.

A analise da sucessao vertical de facies, com base nas seços locais, nostra, cono regra, a seguinte orden, da base para o topo: (a) depositos sub-glaciais; (b) depósitos pro-glaciais de contato com o gelo (c) depósitos próglaciais lacustrinos.

A laboraço de un modelo deposicional nais completo se torna dificil devido a falta de continuidade dos afloramentos e, consequientemente, de suas correlacoles laterais. Apesar destas

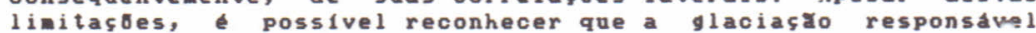
pelas fácies do Grupo Itararé, na area estudada, se desenvolveu dentro de un contexto terrestre, distante da influencia marinha direta. En todos os locais visitados, sempre que ocorrentes, os depósitos de natureza marinha - atribuidos a unidade estratigrafica Budó - recobrem os sedimentos glaciais, o que está de acordo com Piccoli (1989). Cono näo se encontrou, até o presente, associadas a esses siltitos warinhos, feicbes que indicassen a proximidade de geleiras (cono a presensa de clastos pingados), fica claro que o "mar Budo", na area de estudos, năo foi contemporaneo, was posterior ao evento glacial responsável pela geraço das fácies aqui descritas. Esta situaga reflete, assim, uma posiça de borda de bacia para a regiäo. Mais ao norte, em direçă ao centro da bacia, os depósitos glacigenos do Grupo Itararé parecen ter se formado principalente en un contexto glacio-marinho.

Seguindo-se as linhas de pesquisa delineadas neste trabalho, espera-se que, no futuro, estudos mais abrangentes, incorporando informaşos de outras áreas - incluindo-se dados paleontologicos de sub-superficie - possam amilar os conhecimentos relativos ao Grupo Itararé no Rio Grande do Sul, relativamente as caracteristicas de seus sistemas deposicionais, a natureza da glaciaçăo gondwånica nesta regiăo, permitindo, 
inclusive, uma reformulaço estratigrafica para essa importante unidade da Bacia do Paraná.

\section{REFEREMCI AS B I BL I OGRAF I CAS}

CORREA DA SILUA, Z.C., 1978. Ubservaçöes sobre o Grupo Tubargo no Rio Grande do Sul com especial destaque a estratigrafia da Formaçơ It araré. Pesquisas, 9:9-61, Forto Alegre.

LEINZ, V., 1937. Estudos sobre a glaciaça permocarbonifera do sul do Brasil. Bol. Serv. Fom. Prod. Min., DMPH, 21:1-4\%, Kio de Janeiro.

PICCOLI, A.E.M., 1989. Relaços estratigráficas entre as facies Budo e Suspiro (Grupo Itararé) nas folhas de Vila Mova, Lagoa da Keia-Lua e Suspiro, RS. Pesquisas, 22:45-51, forto Alegre.

TOKAZELLI, L.J. \& SOLIAMI JR., E., 1982. Evidencias de atividade glacial no Paleozóico Superior do Rio Grande do Sul, Brasil. In: CONGRESSO BRASILEIRO DE GEOLOGIA, 32, Salvador, Anais..., Sociedade Brasileira de Geologia, v. 4, p. 1378-1384. 
